\title{
Mixed boundary conditions in ocean general circulation models and their influence on the stability of the model's conveyor belt
}

\author{
Uwe Mikolajewicz and Ernst Maier-Reimer \\ Max-Planck-Institut für Meteorologie, Hamburg, Germany
}

\begin{abstract}
When driven under "mixed boundary conditions", coarse resolution ocean general circulation models (OGCMs) generally show a high sensitivity of the present-day thermohaline circulation against perturbations. We will show that an alternative formulation of the boundary condition for temperature, a mixture of prescribed heat fluxes and additional restoring of the sea surface temperature to a climatological boundary temperature with a longer time constant, drastically alters the stability of the modes of the thermohaline circulation. The results from simulations with the Hamburg large-scale geostrophic OGCM indicate that the stability of the mode of the thermohaline circulation with formation of North Atlantic deepwater increases, if the damping of sea surface temperature anomalies is reduced, whereas the opposite is true for the mode without North Atlantic deep water formation. It turns out that the formulation of the temperature boundary condition also affects the variability of the model.
\end{abstract}

\section{Introduction}

The circulation of the oceans represents a major agent in the formation of global climate patterns. Owing to the large heat capacity, even the slow motion transports a substantial fraction of the heat produced by the incoming solar radiation from the tropics to high latitudes. A long time ago, it was speculated [von Humboldt, 1845] that the mild climate in Europe benefits from the fact that the surface circulation of the Atlantic Ocean has a northerly component over almost the entire width. This intuitive finding has been confirmed and quantified since the 1970s by direct estimates of the heat transport by the oceans [e.g., Hastenrath, 1980; Hall and Bryden, 1982; or Roemmich and Wunsch, 1985], and was summarized in a sketch of a closed global thermohaline circulation [Gordon, 1986; Broecker, 1987] popularly known as the "great ocean conveyor".

A key question for model predictions of the future climate is whether the conveyor belt structure of the present-day ocean is stable. This was assumed implicitly in a number of climate models from the 1980 s by the "Q-flux" approach [Hansen et al., 1983] where the oceanic source/sink distribution is prescribed from modem observations. However, mounting evidence from geological records indicates that the thermohaline circulation of the deep ocean has changed substantially in the glacial-interglacial cycle. The distribution of $\delta^{13} \mathrm{C}$ of sedimentary shells of foraminifera [Duplessy et al.,

Copyright 1994 by the American Geophysical Union.

Paper number 94JC01989.

0148-0227/94/94JC-01989\$05.00
1988] strongly suggests that the North Atlantic Deep Water (NADW) outflow was much weaker and shallower during the glacial maximimum than it is today.

The most dramatic climate fluctuation since the termination of the ice age was the Younger Dryas event, a sudden return to glacial conditions in western Europe about 13,000 years ago, lasting for about 1300 years [cf. Mayewski et al., 1993]. There is clear evidence that this event was linked to the absence of NADW formation [e.g., Boyle and Keigwin, 1987]. It has been speculated that it was caused by meltwater input from the retreating glaciers and/or a rerouting of the meltwater of the huge Laurentide ice sheet [e.g., Broecker et al., 1989; Rooth, 1982; Berger and Killingley, 1982]. Some authors claim to have found geological evidence for this hypothesis, whereas others believe that the Younger Dryas event occurred when the global mean meltwater input had an intermediate minimum [e.g., Fairbanks, 1989]. This leaves considerable room for speculations about deglaciation scenarios and their possible impact on the stability of the system, including, also, the geographical position of the input. A small meltwater input from the Scandinavian glaciers, for example, could have a larger impact than a much bigger input from the Laurentide ice sheet through the Mississippi. Berger [1990] argued that the formation of NADW was already shut down before the onset of the Younger Dryas event. The most critical parameter in these speculations is the uncertainty of the exact dating of marine geological records, both of glacier melting and of the species composition at the surface of the North Atlantic, the proxy of both sea surface temperature (SST) and NADW formation. The record of oxygen isotopes from an Greenland ice core suggests that at least the transition back to warm conditions happened within a few decades [Dansgaard et al., 1989]. Recently, Mayewski et al. [1993] concluded from another Greenland ice core that the onset of the Younger Dryas also happened within 20 years. 
Stommel [1961] was the first to show that the different nature of the atmospheric feedbacks for temperature and salinity at the sea surface could favor the existence of multiple steady states of the ocean circulation. Whereas sufficiently small SST anomalies are damped by the anomalous heat fluxes to the atmosphere caused by the SST change, the sea surface salinity (SSS) has no stabilizing negative feedback on the freshwater fluxes; precipitation and river runoff are totally independent of the SSS, and the dependence of the evaporation on salinity is so small that it can be neglected for salinity variations occurring in the open oceans.

This difference in the atmospheric feedback has provided the motivation for the frequent use of mixed boundary conditions as upper boundary conditions for ocean models; the SST is relaxed to a prescribed temperature (either SST or surface air temperature), and the anomalies are thus damped. Typical time constants for the damping are of the order of 1 or 2 months. These relatively short time constants are chosen in view to reproduce the observed climatological SST. In contrast, the freshwater fluxes, as diagnosed from a stationary run with restoring to both surface salinity and temperature, are prescribed and independent of the SSS. Thus SSS anomalies have a significantly longer lifetime than SST anomalies. The surface ocean can act as integrators of freshwater flux anomalies, producing a red spectral response in the SSS to the essentially white input function, as assumed in classical stochastic climate models [Hasselmann, 1976]. One could, of course, think of using the diagnosed heat fluxes from the restoring run in the same way as the freshwater fluxes, ignoring the atmospheric damping of SST anomalies. We are, however, unaware of any successful, long integration of a purely flux-driven OGCM. Our own attempts have failed completely; after a few years the ocean exhibited a drift toward a different climate state caused by the growth of small anomalies, especially in high latitudes and subsequent rearrangement of the global ocean circulation. The sea ice thickness turned out to be the most sensitive quantity. However, the initial drift in an OGCM with a pure flux boundary condition for temperature might be small, so that short integrations might be useful.

Bryan [1986] demonstrated that an OGCM could exhibit distinctly different stationary circulation patterns when driven with identical mixed boundary condition forcing but with different initial conditions. Subsequently, many groups felt challenged to identify sufficient and necessary conditions for the existence of multiple equilibrium states and internal oscillations around and transitions between those states. [e.g., Maier-Reimer and Mikolajewicz, 1989; Marotzke and Willebrand, 1991; Weaver and Sarachik, 1991; Mikolajewicz et al., 1993]. Some of the results found in OGCMs with mixed boundary conditions have been confirmed by experiments with coupled ocean-atmosphere general circulation models (OAGCMs). Manabe and Stouffer [1989] found similar modes in a coupled OAGCM. One mode was very similar to the present mode of the thermohaline circulation of the ocean, the other was characterized by a complete absence of NADW formation.

Although it is clear that only a fully coupled OAGCM can represent the ocean-atmosphere interaction in the climate system, this type of boundary condition has become quite popular and has been used extensively during the last decade by a number of climate simulations with OGCMs. The main reason to attack problems of internal climate variability with ocean only models is the fact that an OGCM alone consumes 2 or 3 orders of magnitude less computer time than a fully coupled OAGCM for the same resolution. A justification for such ocean only experiments can be derived from the experiments of Mikolajewicz et al. [1990], who forced an OGCM with temperature anomalies derived from greenhouse simulations with atmosphere general circulation models (AGCMs) coupled to mixed layer oceans. They obtained changes in sea level due to thermal expansion and variations of the ocean circulation which were of similar magnitude and which were generally comparable to the changes computed later in a greenhouse simulation with a coupled OAGCM [Cubasch et al., 1992].

We emphasize, however, that the nonlinear asymmetric interdependence between density anomalies and mean circulation limits the validity of such arguments. The qualitative discussion by Dickson et al. [1988] on the existence of a threshold salinity for deepwater formation has been confirmed, e.g., by experiments with our model [Weisse et al., 1994]. Since freshwater flux anomalies may change the thermohaline overturning, a substantial feedback on the temperature distribution must be expected. An estimate of the magnitude of the neglected feedback on the atmospheric temperature may be derived again from Mikolajewicz et al. [1990] by comparison of the warming pattern of the atmospheric temperature with the oceanic response. In most parts of the ocean, the resulting SST followed closely the atmospheric structure; in critical regions of deepwater formation, however, the resulting change in SST was much smaller than the imposed boundary condition, and at some isolated locations, even a cooling was predicted.

In this paper we will reexamine the use of mixed boundary conditions in ocean-only models. By considering a series of step-wise transitions from strong SST restoring to an almost decoupled heat flux prescription, we will identify threshold values for the transgression between two different modes of the Atlantic thermohaline circulation in the Hamburg largescale geostrophic OGCM [Maier-Reimer et al., 1993]. The problems connected with mixed boundary conditions are summarized in section 2. After a short description of the LSG OGCM in section 3, results from glaciation and deglaciation experiments are described in section 4 , followed by a short discussion on the simulation of climate variability. A discussion of the results and final conclusions are presented in the last section.

\section{Traditional Mixed Boundary Conditions}

A common feature of global models driven with mixed boundary conditions is the high sensitivity of the present mode of ocean circulation characterized by NADW formation (henceforth, ON mode) against small perturbations. An example is given by Maier-Reimer and Mikolajewicz [1989]. In this modeling study, a rapid transition from the ON mode to the mode without NADW formation (henceforth, OFF mode) was simulated, in accordance with the proposed onset of the Younger Dryas cooling in response to meltwater input into the North Atlantic. They found a strong dependence of the stability of the thermohaline circulation on the location of the meltwater input, and the amount of meltwater needed for the collapse appeared to be astonishingly (perhaps unrealisti- 
cally) small. An additional outflow of only $0.011 \mathrm{~Sv}$ from the St. Lawrence River was sufficient to trigger the transition (see Figure 1). This corresponds to only $20 \%$ of the effective melting rate averaged over several millennia of deglaciation. The termination of the Younger Dryas, however, could not be easily simulated; after switching off the meltwater input the Atlantic remained in the OFF mode, analogous to Bryan's [1986] first experiments. The experiment suggests that the stability of the ON mode is unrealistically low in our OGCM under mixed boundary conditions. Similar results have been obtained by several other modeling groups [Marotzke and Willebrand, 1991; Wright and Stocker, 1993; Tziperman et al., 1994]. In contrast, the OFF mode with no NADW formation turned out to be very stable against perturbations. Again, similar results have been reported by other authors [e.g., Marotzke and Willebrand, 1991]. OGCMs driven by mixed boundary conditions clearly seem to prefer the OFF mode. Recently Hughes and Weaver [1994] found in a two-basin OGCM with idealized forcing that the preference of single modes was highly dependent on details of the chosen bathymetry and of the prescribed temperature and salinity profiles. In some combinations of the forcing factors the ON mode was the preferred mode of the system.

The very low stability of the ON mode in our model was also evidenced by a ,pseudocoupling" experiment with a more realistic forcing pattern. The ocean model with mixed boundary conditions was forced by climatological fluxes with superimposed additional monthly anomalies of surface air temperature, wind stress, and freshwater fluxes derived from a 10-year simulation with an AGCM [Roeckner et al., 1992] forced with observed SSTs [Arpe et al., 1993]. To obtain a record length, suitable for driving an OGCM for thousands of years, the order of the sequences was varied stochastically. The total length of this integration was 3000 years. The resulting time series of the integrated net freshwater flux into the North Atlantic is shown in Figure 2 (top). It is clearly white. The resulting deepwater formation in the North Atlantic in the OGCM is shown in Figure 2 (bottom). After about 380 years the convection was suddenly suppressed and never turned on again. As a consequence, the thermohaline circulation of the Atlantic reverts to the steady state OFF mode. From proxy data (e.g., oxygen isotope records in Greenland ice cores and marine sediments), however, it appears that the real ocean operates in an opposite way. During the last 9000 years the ocean was amazingly constant in the ON mode and not in the OFF mode [Broecker, 1993].

A necessary condition for the formation of NADW in the ON mode is the presence of very saline water in the northern North Atantic. These salty waters are cooled at high latitudes and thus form a water mass dense enough to sink down into the deep ocean. The resulting NADW flows southward in a western boundary current at depths between 2 and $3 \mathrm{~km}$. About $15 \mathrm{~Sv}$ of this water mass finally flow into the Southern Ocean [e.g., Gordon, 1986]. In our model this transport is 17 Sv. The southward outflow is compensated by a northward inflow at the surface. In the North Atlantic this flow brings

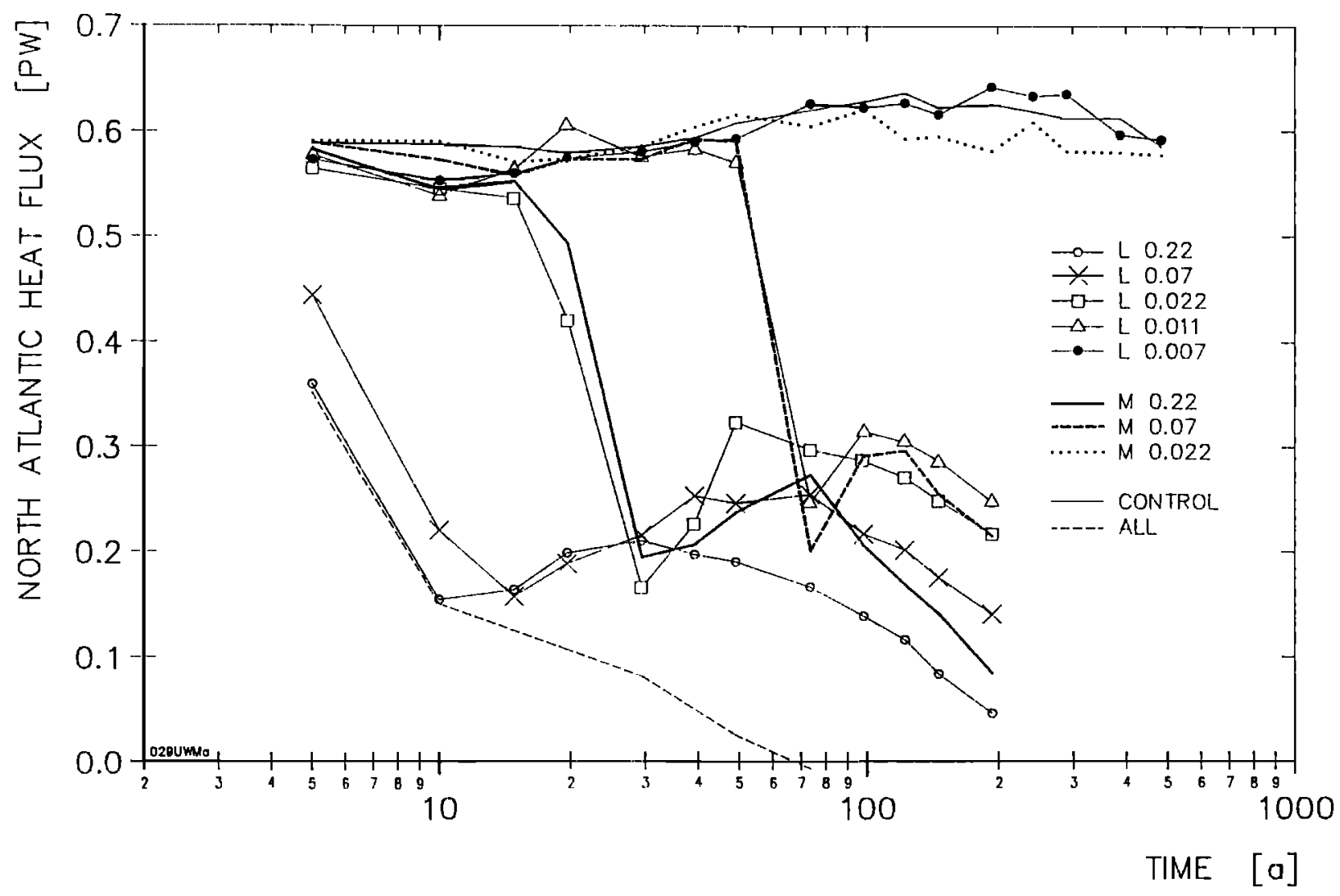

Figure 1. Time series (in years) of North Atlantic and Arctic atmosphere-ocean heat exchange north of $30^{\circ} \mathrm{N}$ (positive values indicate heat loss of the ocean). Experiments with constant meltwater input release either at the St. Lawrence (L) or Mississippi (M). The numbers give the amount of the meltwater input in Sverdrups [after Maier-Reimer and Mikolajewicz, 1989]. 

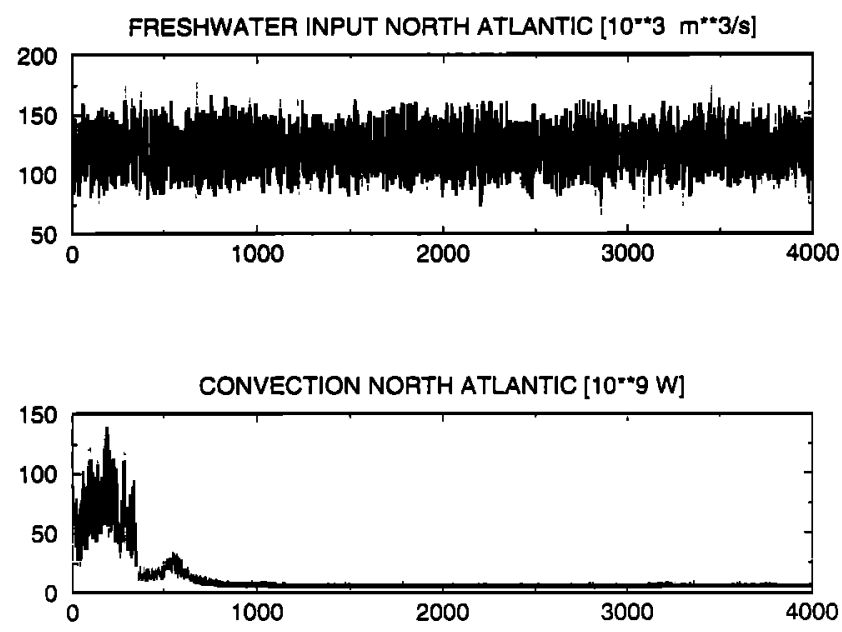

Figure 2. (top) Time series (in years) of prescribed freshwater input into the North Atlantic north of $30^{\circ} \mathrm{N}$ and (bottom) potential energy release through convection in the North Atlantic. All data are annual means without further filtering.

salty surface waters from low latitudes to the regions of NADW formation, thus supporting the high density of the surface waters. The deepest part of the Atlantic is also ventilated by Antarctic bottom water (AABW), which competes with the NADW in filling the deep Atlantic. The densities of these two water masses are almost equal. A slight decrease of the density of the NADW could thus strongly increase the fraction of $A A B W$ in the deep Atlantic and eventually reverse the currents there. As a consequence, the compensating inflow at the surface of warm and salty surface waters would be reduced as well, and the density of the NADW would be reduced even further, finally leading to a complete reversal of the deep circulation of the Atlantic.
With realistic parameters for the temperature dependency of the atmosphere-ocean heat transfer $\left(40 \mathrm{Wm}^{-2} \mathrm{~K}^{-1}\right.$ corresponding to a damping value for SST anomalies of $10^{-5} \mathrm{~ms}^{-1}$ ) from local air-sea heat transfer experiments, mixed boundary conditions damp out SST anomalies within 1 or 2 months (assuming a mixed layer depth of 30 to $50 \mathrm{~m}$ ). In contrast, Frankignoul and Hasselmann [1977], for example, report a typical lifetime of SST anomalies in the North Pacific of 6 months. Thus the parameters lead to an underestimation of the SST variability and an overestimation of the variability of the resultant atmosphere ocean heat fluxes. This is indicated, also, by the too small amplitude of the SST anomalies between the two extreme modes (see Figure 3) in our OGCM with mixed boundary conditions (A third, intermediate mode exists, see Mikolajewicz et al. [1993] for more information) compared to the coupled model of Manabe and Stouffer [1989]. Power et al. [1994] investigated the stability of the ON mode to salinity anomalies in the Labrador Sea and found that the stability was higher when the temperature forcing was switched from a Newtonian relaxation to climatological SST to prescribed heat fluxes without any feedback. Zhang et al. [1993] have also shown from experiments with a single-hemisphere simplified OGCM that the circulation pattern becomes much more stable, if the flux boundary condition for temperature is chosen. Similar results are obtained, if a flux boundary condition with a small additional damping of the SST anomalies are induced with a time constant of the order of 1 year. Both the integrations of Power et al. [1994] and Zhang et al. [1993] were carried out only over a few decades, and their models did not include a sea ice model. From our own experience with the flux only boundary condition for temperature we have strong doubts about the stability on longer timescales.

In the present-day circulation the two components of the buoyancy flux tend to cancel each other. Whereas the heat fluxes favor deepwater formation in polar regions, the fresh-

POT. TEMPERATURF |DEG C |

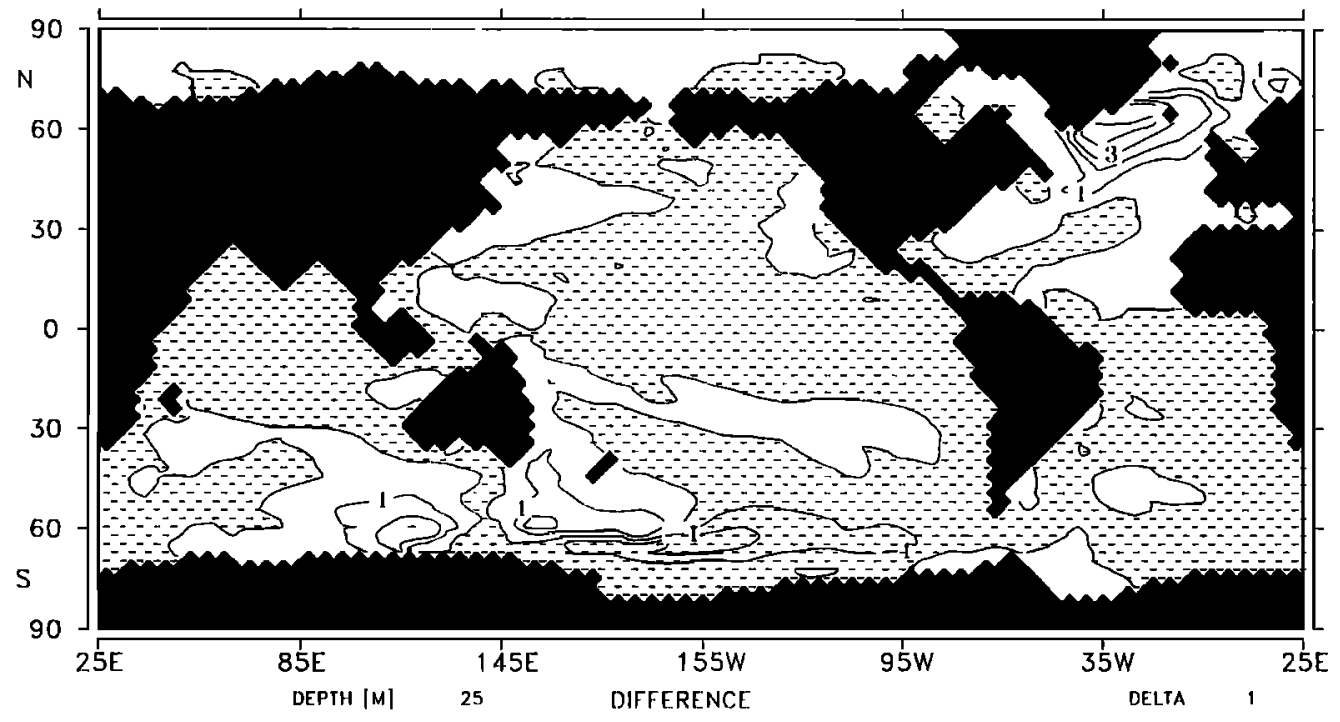

Figure 3. Sea surface temperature (SST) difference between the extreme modes with and without North Atlantic Deep Water (NADW) formation under mixed boundary conditions. The contour interval is $1 \mathrm{~K}$ : shading indicates negative values. The maximum SST anomaly in the North Atlantic is 5.5 $\mathrm{K}$, compared with more than $7 \mathrm{~K}$ in the coupled experiment of Manabe and Stouffer [1989]. 
water fluxes at high latitudes tend to reduce the salinity and thus the density. Similarly, in subtropical regions the evaporation is much stronger than the precipitation, yielding maximal values of the SSS, but the high surface temperatures reduce the surface density. The heat and freshwater fluxes act in the same direction only at the equator, both reducing the surface density.

During the transition from the ON mode to the OFF mode the two components of the buoyancy flux also act in opposite directions. At high latitudes the salinity decreases and reduces density. Through the reduced advection of heat, temperature in the surface layer also decreases, partly compensating the effect of the reduction of salinity. The stability of the system depends critically on the degree of this compensation. The high and probably unrealistic sensitivity of the ON mode to perturbations in ocean circulation models under mixed boundary conditions appears to be largely due to the underestimation of the SST variations.

In the next sections this conjecture is discussed and an attempt is made to overcome at least part of the deficiencies of the mixed boundary conditions, while still retaining the computational efficency in ocean-only simulations.

\section{The Model}

The Hamburg large-scale geostrophic OGCM (LSG) [Maier-Reimer et al., 1993] (see also the early concept of Hasselmann [1982]) is designed for the simulation of ocean dynamics on climatically relevant timescales. It is based on the conservation laws of momentum, heat, and salt and the equations of state and continuity. Aside from the standard approximations (Boussinesq, incompressibility in the equation of continuity, hydrostatic assumption), it also neglects the advection of momentum. The formulation of the model is fully implicit, thus allowing a time step of 1 month. Gravity waves and other fast modes like barotropic Rossby waves are formally included but are strongly damped in this model by the implicit integration scheme. The model contains a simple sea ice component with simplified, viscous rheology.

The model runs at a horizontal resolution of $3.5^{\circ} \times 3.5^{\circ}$ $\mathrm{E}$ grid [Arakawa and Lamb, 1977]. The model has 11 levels, centered at depths of $25,75,150,250,450,700,1000,2000$, 3000,4000 , and $5000 \mathrm{~m}$, and a realistic bathymetry (within the resolution constraints). A more detailed description of the model and its climate is given by Maier-Reimer et al. [1993]. The model has been applied for several sensitivity experiments with mixed boundary conditions [e.g., Maier-Reimer and Mikolajewicz, 1989; Mikolajewicz et al., 1990; Mikolajewicz and Maier-Reimer, 1990], has been incorporated as the ocean component in a coupled OAGCM [e.g., Cubasch et al., 1992], and provides the three-dimensional transport field for the Hamburg global ocean carbon cycle model [e.g., Heinze et al., 1991].

The seasonal cycle is resolved, although we show in this paper annual mean data only. The SST is relaxed to a prescribed monthly mean climatological surface air temperature with account for horizontal advection in the air. A relaxation constant of $40 \mathrm{Wm}^{-2} \mathrm{~K}^{-1}$ is used for temperature corresponding to a damping time of 2 months for an upper layer thickness of $50 \mathrm{~m}$. The momentum fluxes at the surface are taken from monthly mean climatologies [Hellermann and Rosen- stein, 1983]. In a spin-up integration the surface salinities were relaxed toward climatological annual mean surface salinities [Levitus, 1982] with a time constant of 40 days. After the model had achieved a steady state the resultant diagnostic freshwater fluxes were stored and used as forcing for subsequent experiments with mixed boundary conditions. Since the transition from prescribed salinity to mixed boundary conditions drives the circulation into a slightly different mode, the model was integrated for another 4000 years with mixed boundary conditions until steady state was achieved again. The sensitivity experiments were started from this stationary state.

\section{Experiments}

\section{Modified Mixed Boundary Conditions}

In order to test the hypothesis that the high sensitivity of the ON mode against perturbations is due to the formulation of the boundary condition for temperature, four sensitivity experiments with different boundary conditions were carried out. The standard formulation of the upper boundary condition for air-sea heat exchange is

$$
\frac{d T}{d t}=\frac{\kappa\left(T_{a}-T\right)}{c_{p} \rho \Delta z}=\frac{T_{a}-T}{\tau}
$$

where $T$ denotes the ocean surface temperature, $T_{a}$, the climatological effective near-surface air temperature, $K$ is the relaxation constant, $c_{p}$ and $\rho$ are the specific heat and actual density of ocean water, respectively, $\Delta z$ is the thickness of the uppermost layer, and $\tau$ is the damping time. The ocean model was forced with heat fluxes $F_{H c}$ derived from the last spin-up integration with mixed boundary conditions $F_{H c}=\kappa\left(T_{a}-T_{c}\right)$. The only time dependence in the heat fluxes is the annual cycle. An additional damping of anomalies of the SST against the climatology of the model $T_{c}$ was introduced

$$
\frac{d T}{d t}=\frac{F_{H c}}{c_{p} p \Delta z}+\frac{T_{c}-T}{\tau} .
$$

Without damping the background variability together with the highly nonlinear feedback processes associated with deepwater formation and sea ice production would cause a rapid drift of the model into an unrealistic state. Four different damping coefficients were chosen for sensitivity experiments as follows: $\kappa=40,27,16$, and $0.4 \mathrm{Wm}^{-2} \mathrm{~K}^{-1}$, corresponding to damping times $\tau$ of $2,3,5$, and 200 months, respectively. This approach is formally similar to the approach of Zhang et al. [1993], but they used time constants between 200 and 500 days. In modeling studies of the equatorial ocean this type of boundary condition has been used frequently (e.g., in the model comparison study of Stockdale et al., [1993]) but with relaxation to climatological SST. Our experiments will be named E2, E3, E5, and E200. For experiment E2 the boundary conditions are identical to the mixed boundary conditions used in the spin-up and other applications of the model. In the other three cases the models were 
integrated with this type of boundary condition for an additional 4000 years. For E3 and E5 a new steady state was achieved after this time. For E200 the model still exhibited a significant climate drift during the last millennium of the spinup.

\section{Deglaciation Experiment}

We now discuss the sensitivity of the ON mode of the model with these different boundary conditions against input of additional meltwater. Similar to Maier-Reimer and Mikolajewicz [1989], the inflow was released at the Canadian coast of the Labrador Sea. The time history of the prescribed meltwater release for all four experiments is shown in Figure 4a. The meltwater release was increased linearly with time from 0 up to $0.175 \mathrm{~Sv}$ in the year 1000 , after which it was decreased at the same rate. As the freshwater flux field is no longer balanced, the accumulation of the meltwater release leads to a rise of the global mean sea level of $15 \mathrm{~m}$ within the 2000 years of the experiment (Figure 4b). These are not unrealistic values, as the sea level was about $100 \mathrm{~m}$ lower than

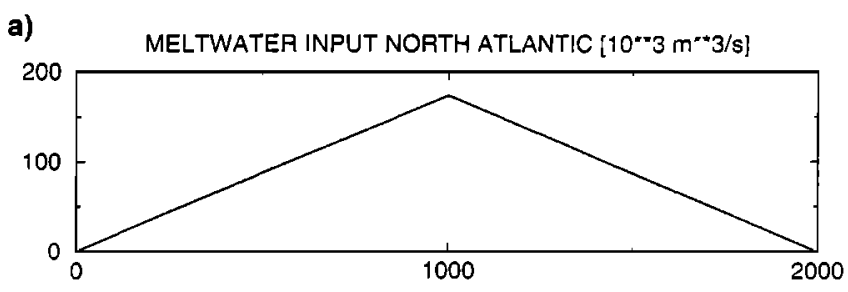

b)

GLOBAL MEAN SEA LEVEL [m]

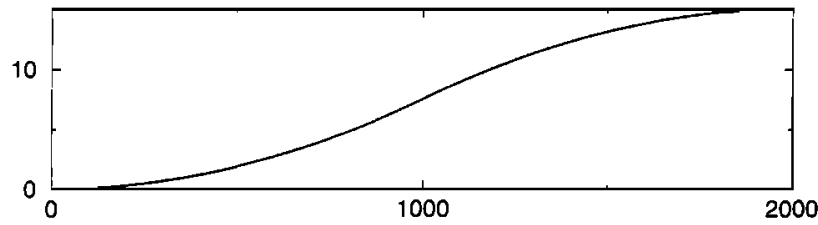

c)

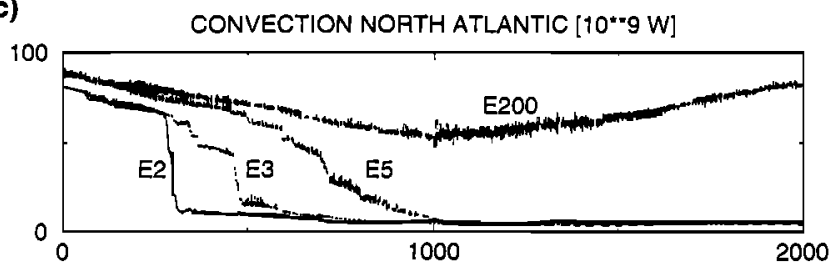

d)

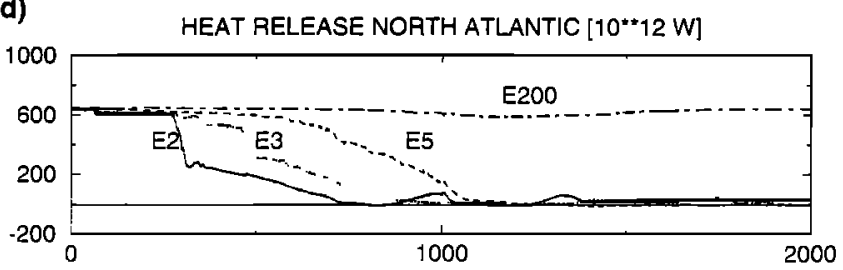

Figure 4. Time series (in years) of (a) prescribed meltwater input into the North Atlantic, (b) resulting change in global mean sea level, (c) convection, and (d) atmosphere-ocean heat exchange in the North Atlantic for deglaciation experiments E2 (solid line), E3 (dotted line), E5 (dashed line), and E200 (dash-dotted line). All data are annual means without further filtering. today during the last glacial maximum $(18,000$ years before present)than it is today. For the last deglaciation, Fairbanks [1989] estimated, from a sea level curve from Barbados corals, a peak of global meltwater flux of more than $0.5 \mathrm{~Sv}$.

Figures $4 \mathrm{c}$ and $4 \mathrm{~d}$ show time series of the atmosphere ocean heat exchange in the North Atlantic (north of $30^{\circ} \mathrm{N}$ ) and the Arctic (negative values indicate heat loss of the ocean) and the total release of potential energy by convection, integrated over the entire North Atlantic and Arctic. The latter quantity has been identified as a good indicator of the formation rate of NADW. In experiment E2 the formation of NADW decreases as the meltwater input increases. Initially, the effect on the oceanic heat release is small. However, after about 280 years the heat transfer from the ocean to the atmosphere drops within 30 years to about $30 \%$ of the original value. This is caused by an abrupt reduction of the formation rate of NADW. After an additional 20 years the deep convection in the North Atlantic has been entirely suppressed. Obviously, the response of the ocean circulation to a linear increase in the meltwater input is highly nonlinear, very close to a step function. The deglaciation rate at the time of the collapse of the ON mode is about $0.05 \mathrm{~Sv}$. The discrepancy to the findings of Maier-Reimer and Mikolajewicz [1989] with a threshold value of $0.01 \mathrm{~Sv}$ may be explained by the different initialization procedure. They left out the spin-up after the switch to the mixed boundary conditions. As a consequence, their control run exhibited some finite variability, and the model therefore was especially vulnerable to perturbations. After the collapse of the NADW formation the northward heat transport of the Atlantic slowly decreases to values below $0.1 \mathrm{PW}$ as the deep thermohaline circulation of the Atlantic is slowly reversed. Finally, the circulation is established in the OFF mode. The timescale of this process is of the order of the flushing time of the deep Atlantic.

In experiment E3 the situation is already different. Until the year $\mathbf{2 8 0}$ the behavior is very similar to the standard case E2; but, instead of starting the nonlinear transition processes as in E2, the response now continues to be almost linear up to year 470 , after which the model shows a similar stepwise response as the standard experiment. The threshold value for the transition in this case is about $0.08 \mathrm{~Sv}$.

In experiment E5 the starting point of the time series of convection in the North Atlantic is slightly higher due to a slight change in the climate of the model caused by the strongly reduced damping of anomalies. In this case the reduction of deepwater formation with increasing meltwater input follows an almost smooth curve with some small steps. The biggest of these steps occurs in year 700, when formation of NADW, again, is reduced to about $50 \%$. At this time the prescribed meltwater input has a strength of $0.12 \mathrm{~Sv}$.

In case E200 of extremely weak damping of SST anomalies the perturbation was insufficient to force a change in the mode of the thermohaline circulation. The formation of NADW becomes weaker as the perturbation runoff increases. The response of the system seems to be almost linear. The interpretation of this experiment, however, is restricted by the fact that no truly steady state was achieved.

As pointed out in the introduction, a strong damping of SST anomalies leads to a weaker stability of the ON mode. In addition, it makes the transition from the ON to the OFF mode much faster and increases the nonlinearity of the response. When the forcing is decreased to a freshwater flux field without additional meltwater input, the ocean circulation 
stayed in the OFF mode in all experiments except for the very weak damping case, where the model always remained in the ON mode and almost returned to its initial state.

To investigate the behavior of the very weak damping case under more severe forcing, another experiment, E200A, was carried out with increased runoff rates. The meltwater input was increased to linearly $0.7 \mathrm{~Sv}$ within 500 years and then again reduced linearly to 0 in the year 1000 , yielding a mean sea level increase of $30 \mathrm{~m}$ (Figure 5). The convection in the North Atlantic decreased linearly until the input reached 0.2 Sv, showed little sensitivity as the input was increased slightly more, and showed a strong reduction of the NADW formation as the meltwater input exceeded $0.33 \mathrm{~Sv}$. As the perturbation forcing again was reduced to 0 , the ocean circulation stayed in the OFF mode.

It should be noted that in all four experiments the system does not respond instantaneously to a change of the meltwater input but with a considerable delay. This is seen in Figure 1 , which shows delays of up to 50 years before the heat flux from the ocean exhibits a significant response to a constant prescribed meltwater input. Competing possible candidates triggering the transition are the quasi-instantaneous release rate or the integrated amount of meltwater released. To test this, three additional experiments for the strong and moderate damping cases were performed with identical boundary conditions but with a linear increase in the discharge rate from 0 in year 0 to $0.175 \mathrm{~Sv}$ in year 500. In Figure 6 the instantaneous discharge rates and the convection in the North Atlantic are shown for all six experiments. It is obvious that the differences between curves with identical formulation of the
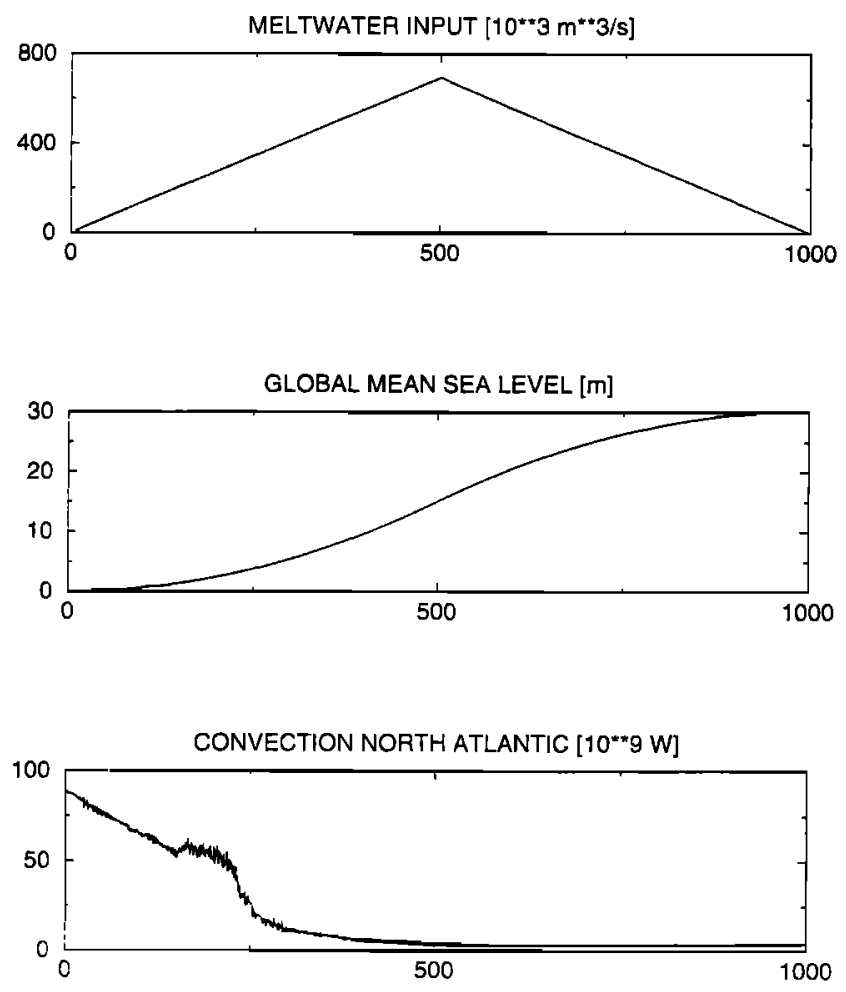

Figure 5. Time series (in years) of (top) prescribed meltwater input into the North Atlantic, (middle) resulting change in global mean sea level, and (bottom) convection in the North Atlantic for deglaciation experiment E200A. All data are annual means without further filtering. temperature boundary condition are relatively small, indicating that the changes in the forcing are sufficient slow to allow for adaptation of the circulation. Clearly, the actual discharge rate is the important parameter for the onset of the transition from the ON mode to the OFF mode, whereas the transition, with these slow variations in the forcing, seems to be rather independent of the total amount of released meltwater. The transition points, where the convection is reduced to $50 \%$ of its original value, correspond to values of $0.05,0.08$, and 0.12 Sv for the experiments with damping times of 2,3 , and 5 , months, respectively. The variation of the meltwater input seems to be sufficiently slow, so that the delay effect can be neglected, although there is a small tendency for a delayed response in the experiments with a more rapid change in the forcing.

For all experiments the patterns of the differences between the SST at the end of the experiment with the system in the OFF mode and the starting field in the ON mode are very similar to the patterns shown in Figure 3. For example, the resulting pattern for experiment E5 is shown in Figure 7. The only significant difference between the experiments is a slight increase of the amplitude as the damping time is increased. In experiment E2 the peak value in the northern North Atlantic is $5.5 \mathrm{~K}$; in $\mathrm{E} 3,6.9 \mathrm{~K}$; and in experiment E5 up to $7.9 \mathrm{~K}$.

\section{Glaciation Experiment}

We consider now the complementary case of the sensitivity of the OFF mode against perturbations. For convenience the three previous integrations E2, E3, and E5, which had achieved the OFF mode, were simply continued with a prescribed net loss of freshwater from the ocean to glaciers. Rather than reducing the river runoff in conjunction with accumulating glaciers, an increased evaporation in the North Atlantic between 40 and $65^{\circ} \mathrm{N}$ was simply added to the prescribed freshwater fluxes. The large spatial scale of the forcing appears to be appropriate, not only from the nature of the simulated process, but also from the destabilizing effect of evaporation. A strong local forcing would have produced very high salinities at the surface and thus would have immediately started local deep convection. After the end of the deglaciation experiment in the year 2000 the freshwater loss increased linearly with time at a rate of about $0.0778 \mathrm{~Sv} / 1000$ years until the year 3900 (when all experiments had made the transition to the $\mathrm{ON}$ mode), after which the additional forcing was reduced again (Figure 8), ensuring that at the end of the integrations both the net freshwater fluxes were balanced again and the total amount of water in the oceans had reached its initial state.

In all three experiments a weak effect on the convection and the oceanic heat loss is seen around year 2700. This corresponds to a net evaporation of approximately $0.055 \mathrm{~Sv}$. In standard mixed boundary case E2 the net evaporation required to bring the model back into the $\mathrm{ON}$ mode was about $0.124 \mathrm{~Sv}$. The transition in the year 3600 happens in a sudden, steplike manner with strong overshooting both in convection and atmosphere-ocean heat exchange. In experiment E3 the ocean circulation switches into the ON mode around the year 3400 , when the net evaporation has reached a value of $0.109 \mathrm{~Sv}$. In experiment E5 the switch to the ON mode happens even earlier in the year 3100 at a net freshwater loss 


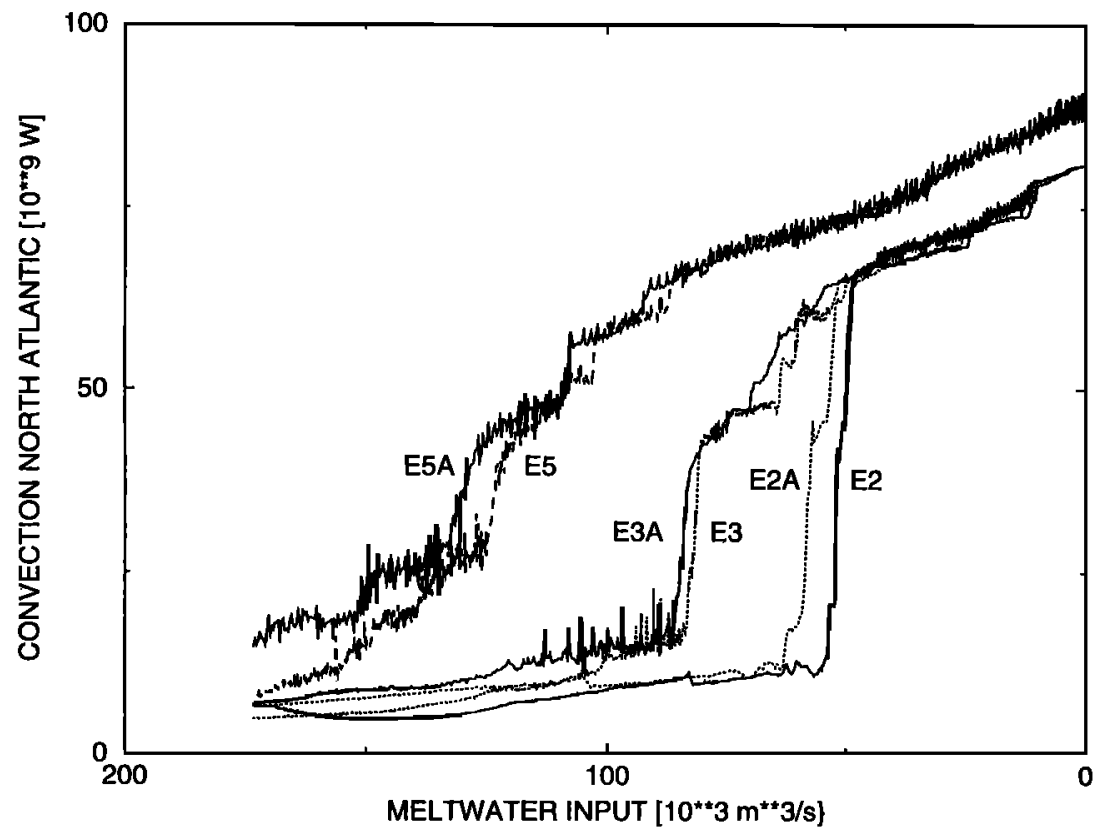

Figure 6. Convection in the North Atlantic versus additional meltwater input for the first 1000 years of experiments E2, E3, and E5 and the first 500 years from three additional experiments with doubled increase rates of the meltwater input. All data are annual means without further filtering.

of about $0.086 \mathrm{~Sv}$. In all cases the transition is a very sudden and steep process with regard to convection. The overshoot decreases as the damping time increases. For the atmosphereocean heat exchange the transition becomes much smoother as the damping is reduced. Overshooting is restricted to case E2. Again, an increase of the time constant for damping leads to a higher stability of the ON mode and a decrease of the stability of the OFF mode.

Figure 9 shows the hysteresis curves for the three experiments. The lines for E2 and E3 are not closed. A perfect closure cannot be expected, as the experiments were not continued in a cyclic steady state. Closed curves would result from a single cycle only, if the variation of the forcing was sufficiently slow for the model to adapt to an equilibrium at the zero flux points. This assumption is approximately valid for most of the curves, the violations being most pronounced for E2.

The rather arbitrarily chosen patterns of the freshwater flux are a limitation for the interpretation of this approach. Maier-Reimer and Mikolajewicz [1989] showed that the location of the perturbation is a critical factor for the response of the ocean circulation to prescribed meltwater release. The stability of the system is also dependent on the climatological freshwater flux. Tziperman et al. [1994] have shown recently that even a moderate change of the relaxation constant for salinity in the spin-up has a distinct influence on the stability of the total sytem.

The hysteresis curves clearly show that the model, when forced with the standard mixed boundary conditions, clearly favors the OFF mode. Whereas a perturbation of $0.05 \mathrm{~Sv}$ is

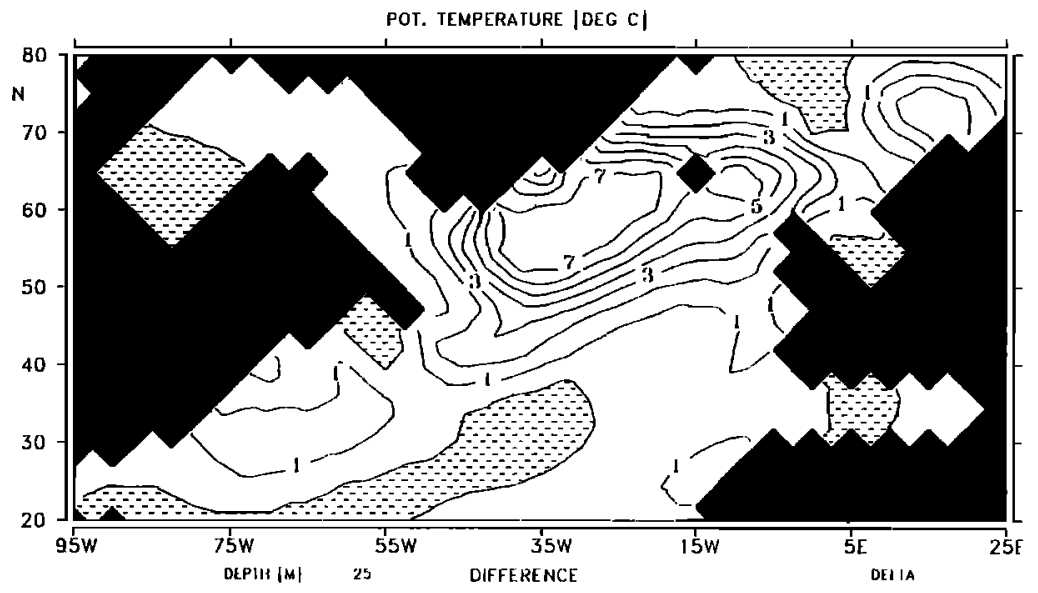

Figure 7. North Atlantic SST difference in experiment E5 between years 0 and 2000. The contour interval is $1 \mathrm{~K}$; shading indicates negative values. 
a)

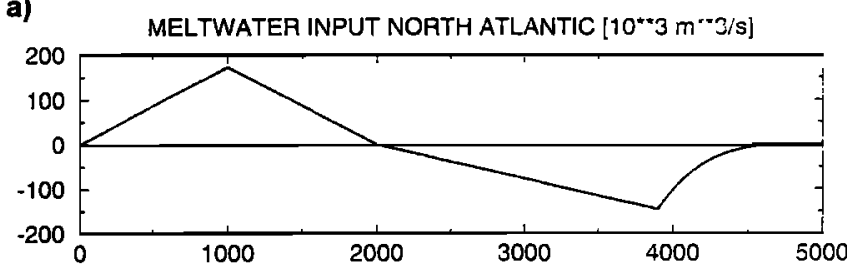

b)

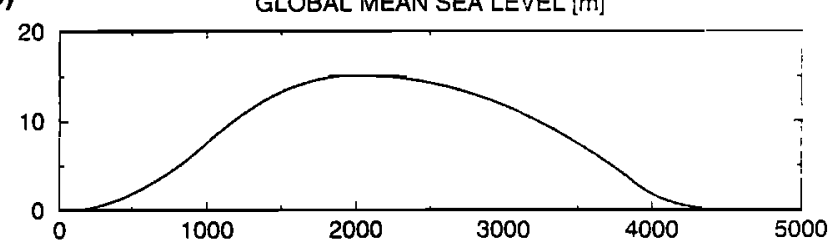

c)

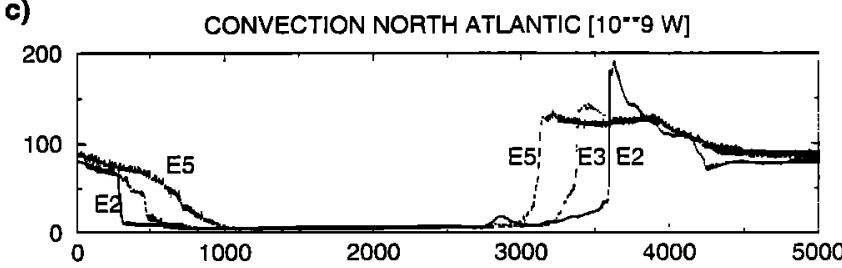

d)

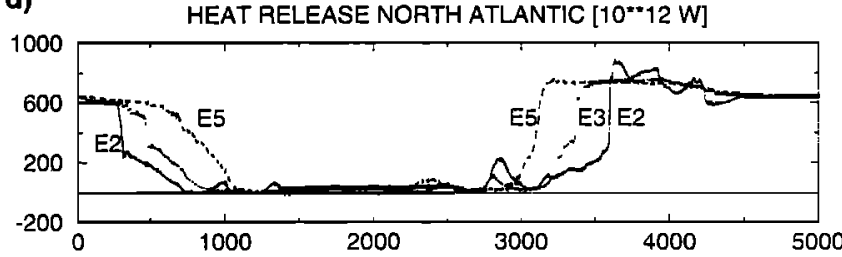

Figure 8. Time series (in years) of (a) prescribed meltwater input into the North Atlantic, (b) resulting change in global mean sea level, (c) convection, and (d) atmosphere ocean heat exchange in the North Atlantic for experiments E2 (solid line), E3 (dotted line), and E5 (dashed line). All data are annual means without further filtering.

sufficient to trigger the transition from the $\mathrm{ON}$ mode to the OFF mode, a net freshwater loss of $0.12 \mathrm{~Sv}$ is required to return to the initial state again. This explains the results of the white noise forcing experiment discussed in the introduction. The level of the noise forcing is sufficient to leave the ON mode but not to leave the OFF mode. This would require a noise level almost 3 times as high. At this higher noise level the transition from the ON mode to the OFF mode would be very likely, whereas the probability for the inverse transition would be much smaller. Thus most of the time the model would be in the OFF-mode.

Increasing the damping time constant for SST anomalies by $50 \%$ drastically alters the situation. Now the likelihood of the occurrence of both modes is almost equal. The required minimum perturbations in the forcing are $0.08 \mathrm{~Sv}$ and 0.11 Sv, respectively. A further increase of the time constant leads to a situation where the model prefers the ON mode. For E5 the threshold values are $0.086 \mathrm{~Sv}$ and $0.125 \mathrm{~Sv}$. In this case the stability of the OFF mode is smaller than the stability of the ON mode.

In all three cases the transition from the OFF to the ON mode occurs nearly as step function. This is consistent with the rapid end of the Younger Dryas reported in the literature.
The strong nonlinear response for the transition from the $O N$ mode to the OFF mode gradually changes into an almost linear response as the damping time increases. For E5 this would require a strong and rapid change in the forcing to produce a transition as rapid as observed for the onset of the Younger Dryas.

Experiment E200A was also continued, reaching a maximum perturbation evaporation of $0.29 \mathrm{~Sv}$ in year 2900 and subsequently a gradual return of both freshwater flux and global mean sea level to its initial unperturbed values in the year 5000. The results (not shown) are consistent with the other experiments. The threshold for the transition from the OFF mode to the ON mode was $0.06 \mathrm{~Sv}$, the smallest value of all experiments. This should be taken only as a rough estimate of the required numbers, however, as we did not attain a basic stationary reference state for this time constant.

\section{Influence on variability}

Our results emphasize the importance of a realistic formulation of the upper boundary condition for temperature, if one intends to draw conclusions from ocean only model climate experiments. The estimation of $\tau$ from measurements requires a consistent, global data set. Whereas it is relatively easy to obtain measurements of SST, the measurements of all of the components contributing to the net heat flux (e.g., incoming solar radiation, outgoing long wave radiation, latent and sensible heat exchange) are not so straightforward, and thus the data base is sparse.

To avoid all these difficulties, we choose to use data from a realistic AGCM to derive an estimate for $\tau$. An AGCM [Roeckner et al., 1992] in a T42 resolution was forced with observed SSTs of the years 1979-1988 [Arpe et al., 1993]. From this run, monthly means were computed. After the mean annual cycle was subtracted, monthly anomalies of SST and net heat-exchage between ocean and atmosphere were computed. Damping terms were computed by linear regression from these anomalies. In the absence of sea ice this gave a mean value of $16 \mathrm{Wm}^{-2} \mathrm{~K}^{-1}$, corresponding to a damping time of about 5 months, although the spatial scatter was quite large (standard deviation of $11 \mathrm{Wm}^{-2} \mathrm{~K}^{-1}$ ). Thus the behavior of the model with a damping time of 5 months appears to be the most realistic.

As a test, the stochastic forcing experiment mentioned in the introduction was repeated with this type of boundary condition and a damping time $\tau$ of 5 months. The OGCM was driven with monthly anomalies of near-surface air temperature, wind stresses and net heat and freshwater fluxes from the above mentioned AGCM integration. From the available 10 years of forcing, consistent anomaly fields were chosen randomly under the constraint that the anomalies were applied in the season for which they were computed. The resulting time series for freshwater flux in the North Atlantic (forcing) and convection in the North Atlantic are shown in Figure 10. The formation of NADW shows some variations, but the formation of NADW is never totally suppressed during the 3000 years of this experiment. The unrealistic transition from the ON mode into the OFF mode when the model is forced with realistic atmospheric variability is no longer present (compare with Figure 3). The time series of the mass 


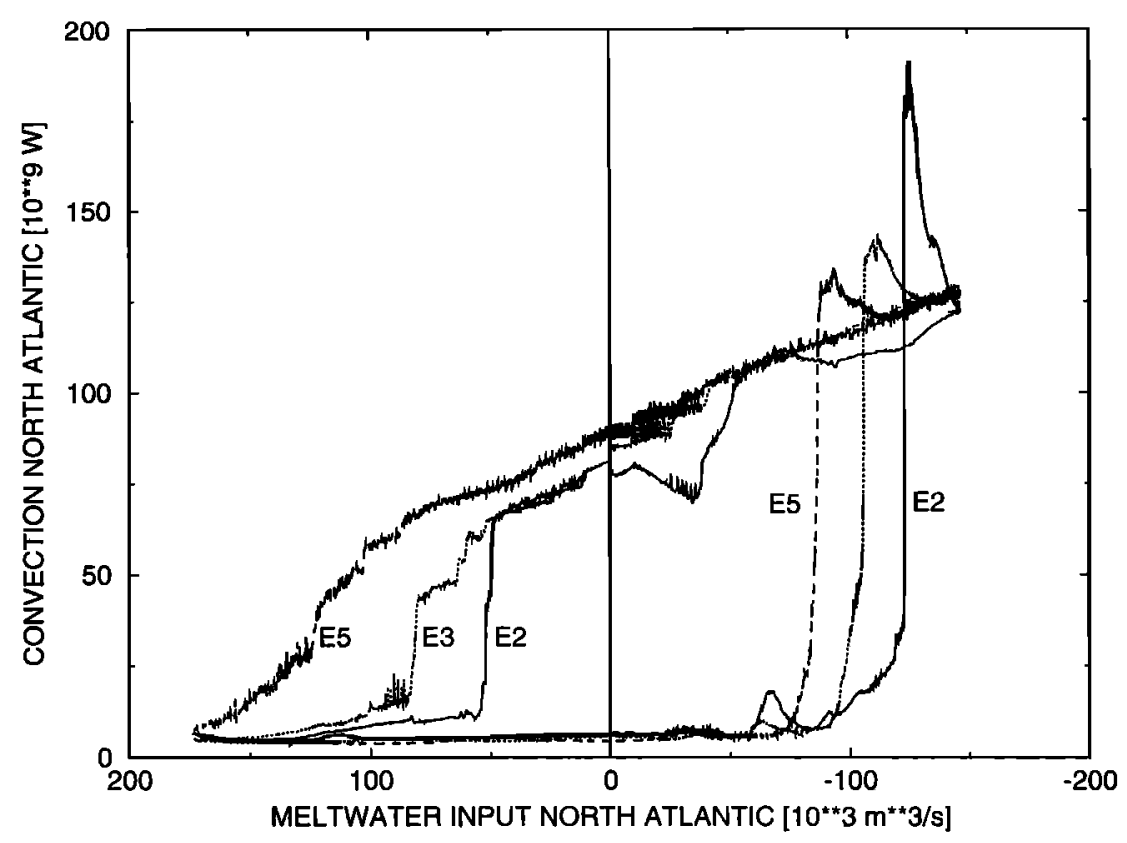

Figure 9. Hysteresis curve of the formation of NADW (indicated by the convection in the North Atlantic) versus amount of freshwater input/removal for experiments E2 (solid, thin line), E3 (dashed, thin line) and E5 (solid, thick line). Positive values for the meltwater input indicate deglaciation. All data are annual means without further filtering. The time history of the experiment corresponds to counterclockwise propagation along the curves.
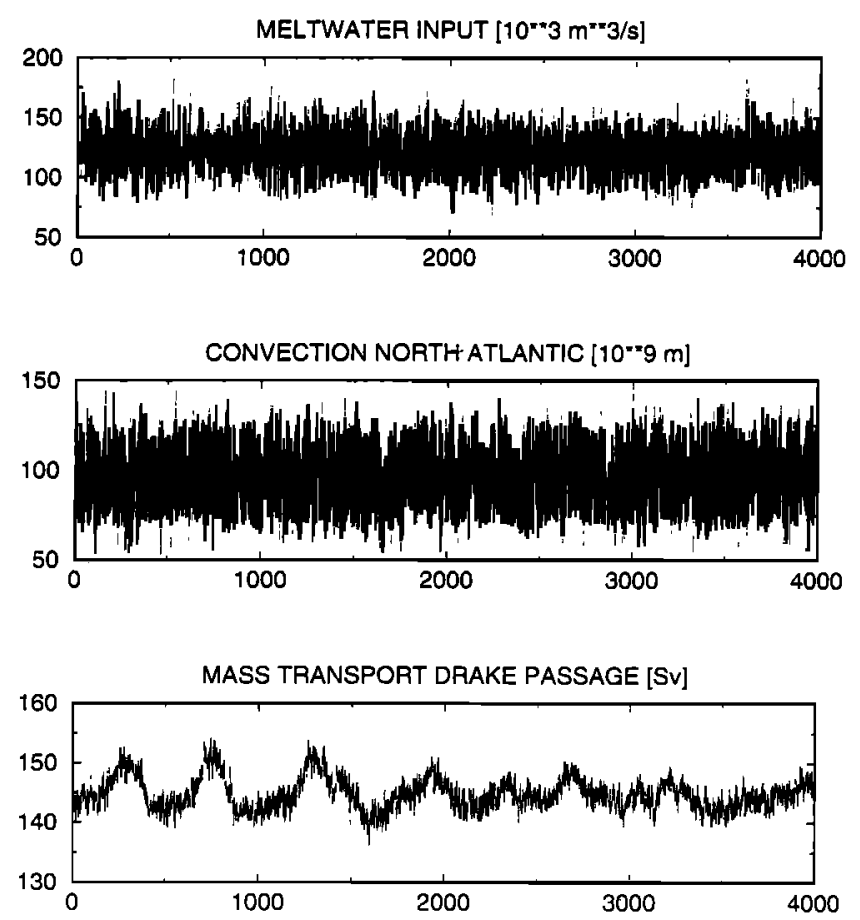

Figure 10. Time series (in years) of (top) prescribed freshwater input into the North Atlantic, (middle) convection in the North Atlantic, and (bottom) mass transport through Drake Passage of the stochastic forcing experiment with a damping coefficient of $16 \mathrm{Wm}^{-2} \mathrm{~K}^{-1}$, corresponding to a damping time of 5 months. transport of the Antarctic Circumpolar Current through the Drake Passage shows some oscillations with a typical timescale of slightly less than 500 years.

The 320-year oscillation found in an earlier stochastically forced experiment [Mikolajewicz and Maier-Reimer, 1990] was affected by the formulation of the boundary conditions as well. With $\tau=5$, the oscillation could not be reproduced with the same variance of the prescribed patterns of fresh water flux; the amplitude of the noise forcing had to be increased by a factor of 8 for the oscillation to occur. The period now has changed to slightly less than 500 years. The resulting oscillations were very similar to those obtained with the noise forcing derived from the AGCM simulation. Details will be discussed in a future paper.

\section{Conclusions}

Some aspects of the probably unrealistic behavior of OGCMs forced with the widely used mixed boundary conditions for temperature and salinity can be cured by prescribing a combination of heat fluxes and near-surface air temperatures with weaker feedback, instead of near-surface air temperatures alone. The effect of this modification on the stability of the conveyor belt circulation against perturbations is large, increasing the stability of the system drastically. Whereas sudden transitions from the ON mode to the OFF mode require sudden changes in the forcing, the reverse transition is always a catastrophic event. In the limit of pure prescription of heat fluxes as atmospheric boundary condition 
for temperature, the system, again, becomes unstable, as small perturbations caused by background noise in the model grow without negative feedback. As a consequence of the enhanced stability of the conveyor, the tendency to exhibit secular oscillations is reduced.

From an uncoupled AGCM simulation the parameter for the SST damping was estimated to be about $16 \mathrm{Wm}^{-2} \mathrm{~K}^{-1}$ (corresponding to 5 months in our model); but as the system reacts quite sensitively on the choice of the parameter, a more proper estimate of it through comparison with coupled OAGCM simulations is needed. Meltwater experiments would be especially helpful to test the stability of the present mode of ocean circulation. Thus the behavior of the model with this feedback parameter appears to be at least a first iteration step toward a more realistic formulation of mixed boundary conditions. Recently, S. Rahmstorf and J. Willebrand (The role of temperature feedback in stabilising the thermohaline circulation, submitted to Journal of Physical Oceanography, 1994) showed that they can get a similar stabilization of the thermohaline circulation by using different damping constants for small-scale and large-scale SST anomalies. Wright and Stocker [1993] found a stabilization effect when coupling their 2.5-dimensional model to an energy balance model. The coupling of the two-dimensional energy balance model of North et al. [1983] to the LSG OGCM is currently going on and should be a next step to have a more realistic formulation of the upper boundary condition for temperature in ocean only climate simulations.

Acknowledgements. We appreciate the comments of Klaus Hasselmann. We gratefully acknowledge the assistance of Petra Besemann in carefully reading this manuscript and of Stefan Schultz, Norbert Noreiks, and Marion Grunert for assistance with the figures. This work was funded by the Deutsche Forschungsgemeinschaft through the Sonderforschungsbereich 318.

\section{References}

Arakawa, A., and V. R. Lamb, Computational design of the basic dynamical processes of the UCLA general circulation model, Methods Comput. Phys., 17, 173-265, 1977.

Arpe, K., L. Bengtsson, and E. Roeckner, The Impact of sea surface temperature anomalies on the variability of the atmospheric circulation in the ECHAM3 model, in Research Activities in atmospheric and oceanic modelling, edited by $\mathrm{G}$. Boer, pp. 7.18-7.20, WMO Report No. 18, Geneva, 1993.

Berger, W. H., The Younger-Dryas cold spell-A quest for causes, Palaeogeogr. Paleaoclimatol. Paleaoecol., 89, 219-237, 1990.

Berger, W. H., and J. S. Killingley, The Worthington effect and the origin of the Younger Dryas, J. Mar. Res., 40 suppl., $27-$ 38., 1982.

Boyle, E. A., and L. Keigwin, North Atlantic thermohaline circulation during the past 20,000 years linked to high-latitude surface temperature, Nature 330, 35-40, 1987.

Broecker, W. S., The great ocean conveyor, Nat. Hist. Mag., 7482, Oct., 1987.

Broecker, W. S., The strength of the Nordic heat pump, in The last Deglaciation: Absolute and Radiocarbon Chronologies, NATO ASI Ser., Ser. I, edited by E.Bard and W. S.Broecker, pp. 173-182, Springer Verlag , New York, 1993.

Broecker, W. S., J. P. Kennett, B. P. Flower, J. T. Teller, S. Trumbore, G. Bonani, and W. Wolfli, Routing of meltwater from the
Laurentide Ice Sheet during the Younger Dryas cold episode, Nature, 341, 318-321, 1989.

Bryan, F., High latitude salinity effects and interhemispheric thermohaline circulations, Nature, 305, 301-304, 1986.

Cubasch, U., K. Hasselmann, H. Höck, E. Maier-Reimer, U. Mikolajewicz, B. D. Santer, and R. Sausen, Time-dependent greenhouse warming computations with a coupled oceanatmosphere model, Clim. Dyn., 8, 55-69, 1992.

Dansgaard, W., J. W. C. White, and S. J. Johnsen, The abrupt termination of the Younger Dryas climate event, Nature, 339, 532-534, 1989.

Dickson, R. R., J. Meincke, S.-A. Malmberg, and A. J. Lee, The "Great Salinity Anomaly" in the northern North Atlantic 19681982, Prog. Oceanogr., 20, 103-151, 1988.

Duplessy, J. C., N. J. Shackleton, R. Fairbanks, L. Labeyrie, L. Oppo, and N. Kallel, Deepwater source variations during the last climatic cycle and their impact on the global deepwater circulation, Paleoceanography, 3, 343-360, 1988.

Fairbanks , R. G., A 17,000-year glacio-eustatic sea level record: Influence of glacial melting rates on the Younger Dryas event and deep-ocean circulation, Nature, 342, 637-642, 1989.

Frankignoul, C. and K. Hasselmann, Stochastic climate models, II, Application to sea-surface temperature anomalies and thermocline variability, Tellus, 29, 289-305, 1977.

Gordon, A. L., Interocean exchange of thermocline water, $J$. Geophys. Res., 91, 5037-5046, 1986.

Hall, M. M., and H. L. Bryden, Direct estimates and mechanisms of ocean heat transport, Deep Sea Res., Part A, 29, 339-359, 1982.

Hansen, J., A. Lacis, D. Rind, G. Russell, P. Stone, I. Fung, R. Ruedy, and J. Lerner, Climate sensitivity: Analysis of feedback mechanisms, in Climate Processes and Climate Sensitivity, Geophys. Monogr. Ser, vol. 29, edited by J. E. Hansen and T Takahashi, pp. 130-163, AGU, Washington, D. C., 1983.

Hasselmann, K., Stochastic climate models, I, Theory, Tellus, 28, 473-485, 1976.

Hasselmann, K., An ocean model for climate variability studies, Progr. Oceanogr., 11, 69-82, 1982.

Hastenrath, S., On meridional heat transports in the world ocean, J. Phys. Oceanogr., 12, 922-927, 1980.

Heinze, C., E. Maier-Reimer, and K. Winn, Glacial $\mathrm{pCO}_{2}$ reduction by the world ocean: experiments with the Hamburg carbon cycle model, Paleoceanography, 6, 395-430, 1991.

Hellermann, S., and M. Rosenstein, Normal monthly windstress over the World Ocean with error estimates, J. Phys. Oceanogr., 13, 1093-1104, 1983.

Hughes, T. M. C., and A. J. Weaver, Multiple equilibria of an asymmetric two-basin ocean model, J. Phys. Oceanogr., 24, 619-637, 1994.

von Humboldt, A., Kosmos. Entwurf einer physischen Weltbeschreibung, Erster Band, 453 pp., Cotta'scher Verlag, Stuttgart und Tübingen, Germany, 1845.

Levitus, S., Climatological atlas of the World Ocean, NOAA Prof. Pap. 13, 173 pp., 1982.

Maier-Reimer, E., and U. Mikolajewicz, Experiments with an OGCM on the cause of the Younger Dryas, in Oceanography 1988, edited by A. Ayala-Castañares, W. Wooster, and A Yáñez-Arancibia, pp. 87-100, Universidad Nacional Autónoma de México Press, Mexico Cíty, 1989.

Maier-Reimer, E., U. Mikolajewicz, and K. Hasselmann, Mean circulation of the Hamburg LSG OGCM and its sensitivity to the thermohaline surface forcing, J. Phys. Oceanogr., 23, 731757, 1993.

Manabe, S., and R. J. Stouffer, Two stable equilibria of a coupled ocean atmosphere model, J. Clim., 1, 841-866, 1989.

Marotzke, J., and J. Willebrand, Multiple equilibria of the global thermohaline circulation, J. Phys. Oceanogr., 21, 1372-1385, 1991.

Mayewski, P. A., L. D. Meeker, S. Whitlow, M. S. Twickler, M. 
C. Morrison, R. B. Alley, P. Bloomfield and K. Taylor, The atmosphere during the Younger Dryas, Science, 261, 195-197, 1993.

Mikolajewicz, U., and E. Maier-Reimer, Internal secular variability in an ocean general circulation model, Clim. Dyn., 4, 145-156, 1990.

Mikolajewicz, U., B. D. Santer, and E. Maier-Reimer, Ocean response to greenhouse warming, Nature, 345, 589-593, 1990.

Mikolajewicz, U., E. Maier-Reimer, T. J. Crowley and K.-Y. Kim, Effect of Drake and Panamanian gateways on the circulation of an ocean model, Paleoceanography, 8, 409-426, 1993.

North, G. R., J. G. Mengel, and D. A. Short, Simple energy balance model resolving the seasons and the continents: Application to the astronomical theory of the ice ages, J. Geophys. Res., 88, 6576-6586, 1983.

Power, S. B., A. M. Moore, D. A. Post, N. R. Smith, and R. Kleeman, On the stability of North Atlantic deep water formation in a global general circulation model, J. Phys. Oceanogr. 24, 904-916, 1994.

Roeckner, E., et al., Simulation of the present-day climate with the ECHAM model: Impact of model physics and resolution, Rep. 93, pp. 171, Max-Planck-Inst. für Meteorol., Hamburg, Germany, 1992.

Roemmich, D., and C. Wunsch, Two transatlantic sections: Meridional circulation and heat flux in the subtropical North Atlantic Ocean, Deep Sea Res., Part A, 32, 619-664, 1985.

Rooth, C., Hydrology and ocean circulation, Progr. Oceanogr, 11, 131-149, 1982.

Stockdale, T., D. Anderson, M. Davey, P. Delecluse, A. Kattenberg, M. Latif, and T. Yamagata, TOGA numerical experimentation group: intercomparison of tropical ocean GCMs, Rep.
WCRP-79, WMO/TD-545, 37 pp., World Meteorol. Organ., Geneva, 1993.

Stommel, H., Thermohaline convection with two stable regimes of flow, Tellus, 13, 224-230, 1961.

Tziperman, E., J. R. Toggweiler, Y. Feliks, and K. Bryan, Instability of the thermohaline circulation with respect to mixed boundary conditions: Is it really a problem for realistic models?, J. Phys. Oceanogr., 24, 217-232, 1994.

Weaver, A. J., and E. S. Sarachik, The role of mixed boundary conditions in numerical models of the oceans climate, J. Phys. Oceanogr., 21, 1470-1493, 1991.

Weisse, R., U. Mikolajewicz, and E. Maier-Reimer, Decadal Variability of the North Atlantic in an ocean general circulation model, J. Geophys. Res., 99, 12,411-12,421, 1994.

Woodruff, S. D., R. J. Slutz, R. L. Jenne, and P. M. Steurer, A comprehensive ocean-atmosphere data set, Bull. Amer. Meteorol. Soc., 68, 1239-1250, 1987.

Wright, D. G., and T. F. Stocker, Younger Dryas experiments, in Ice in the Climate System, edited by W. R. Peltier, pp. 395-416, Springer-Verlag, New York, 1993.

Zhang, S., R. J. Greatbatch and C. A. Lin, A reexamination of the polar halocline catastrophe and implications for coupled ocean-atmosphere modelling, J. Phys. Oceanogr, 23, 287-299, 1993.

E. Maier-Reimer and U. Mikolajewicz, Max-Planck-Institut für Meteorologie, Bundesstrasse 55, D-20146 Hamburg, Federal Republic of Germany.

(Received March 25, 1994; revised July 1, 1994; accepted August 1, 1994.) 